\title{
Bromodomains as therapeutic targets
}

\section{Susanne Muller, Panagis Filippakopoulos and Stefan Knapp*}

Acetylation of lysine residues is a post-translational modification with broad relevance to cellular signalling and disease biology. Enzymes that 'write' (histone acetyltransferases, HATs) and 'erase' (histone deacetylases, HDACs) acetylation sites are an area of extensive research in current drug development, but very few potent inhibitors that modulate the 'reading process' mediated by acetyl lysines have been described. The principal readers of $\varepsilon-N$-acetyl lysine ( $\left.K_{\text {ac}}\right)$ marks are bromodomains (BRDs), which are a diverse family of evolutionary conserved protein-interaction modules. The conserved BRD fold contains a deep, largely hydrophobic acetyl lysine binding site, which represents an attractive pocket for the development of small, pharmaceutically active molecules. Proteins that contain BRDs have been implicated in the development of a large variety of diseases. Recently, two highly potent and selective inhibitors that target BRDs of the BET (bromodomains and extra-terminal) family provided compelling data supporting targeting of these BRDs in inflammation and in an aggressive type of squamous cell carcinoma. It is likely that BRDs will emerge alongside HATs and HDACs as interesting targets for drug development for the large number of diseases that are caused by aberrant acetylation of lysine residues.

Lysine acetylation is similar to protein is particularly abundant in large phosphorylation in its prevalence as a post- macromolecular complexes that are present in translational modification and also has a large the cell nucleus, suggesting a key role of effect on the physicochemical property of the modified residue. The addition of an acetyl moiety to the side-chain nitrogen of lysine leads to neutralisation of charge, which can significantly influence protein conformation and protein-protein interactions, thus resulting in the modulation of enzyme activities and protein assembly (Ref. 1). The central role of $\varepsilon-N-$ acetylation of lysine residues $\left(K_{\mathrm{ac}}\right)$ is reflected by the large number of acetylation sites that have been identified in proteins (Ref. 2). Acetylation acetylation in the regulation of chromatin and transcriptional control. In particular, the unstructured tails of histones are hotspots of acetyl lysine modification. Histone acetylation levels have been associated with an open chromatin architecture and transcriptional activation, but specific marks have also been linked to chromatin condensation (e.g. H4K16) (Refs 3, 4), regulation of metabolism (Ref. 5) and DNA repair (Ref. 6). Acetylation of transcription factors can either stimulate or silence gene

Department of Clinical Medicine, Structural Genomics Consortium, University of Oxford, Oxford, UK.

*Corresponding author: Stefan Knapp, Department of Clinical Medicine, Structural Genomics Consortium, University of Oxford, Old Road Campus Research Building, Roosevelt Drive, Oxford OX3 7LD, UK. E-mail: stefan.knapp@sgc.ox.ac.uk

Accession information: doi:10.1017/S1462399411001992; Vol. 13; e29; September 2011 (c) Cambridge University Press 2011. Re-use permitted under a Creative Commons Licence - by-nc-sa. 
transcription, and inappropriate acetylation levels have been associated with aberrant transcription of disease-promoting genes in cancer and inflammation, instigating the development of inhibitors for histone deacetylases (HDACs) (Ref. 7) and histone acetyltransferases (HATs) (Ref. 8).

Recruitment of proteins to macromolecular complexes by acetylated lysine residues is mediated by bromodomains (BRDs), which are evolutionarily highly conserved proteininteraction modules that recognise $\varepsilon-N$-lysine acetylation motifs (Ref. 9). However, BRDs in BRD4 have recently been shown to bind propionylated and butyrylated lysine residues (Ref. 10). BRDs are named after the Drosophila gene brahma where the BRD sequence motif was first reported (Refs 11, 12). Since then, BRDs have been identified in a number of nuclear proteins such as HATs (Ref. 13), ATP-dependent chromatin-remodelling complexes (Ref. 14), methyltransferases (Refs 15, 16) and transcriptional coactivators (Refs 17, 18, 19) (Table 1).

\section{Role of BRD proteins in chromatin biology}

BRDs have an important role in the targeting of chromatin-modifying enzymes to specific sites. Often they act with other protein-interaction modules to guarantee a high level of targeting specificity for these essential enzymes. For example, the methyltransferase ASH1L contains a combination of one BRD and one plant homology domain (PHD), as well as a bromoadjacent homology domain (BAH) (Ref. 20). ASH1L is a member of the trithorax group of transcriptional activators. In Drosophila, ASH1L activates ultrabithorax expression, and mammalian homologues have been associated with actively transcribed genes. Another example of a multidomain methyltransferase containing a BRD is the mixed lineage leukaemia (MLL) gene product (Ref. 21), which is an essential gene and acts as a key regulator of the expression of many genes. MLL is required for proper segment identity in mammals, it displays haplo-insufficiency and regulates self-renewal of haematopoietic stem cells by controlling HOX (homeobox) gene expression (Refs 22, 23, 24).

In addition, the HATs CREBBP and EP300 contain several protein-interaction modules, including one BRD, and zinc finger and KIX domains (Ref. 25). Both proteins share a high degree of sequence similarity and act as transcriptional coactivators that control a large variety of biological processes, including cell growth, genomic stability, development, neuronal plasticity and memory formation, as well as energy homeostasis (Ref. 26). CREBBP is a coactivator of the cAMP response elementbinding CREB transcription factor. The fundamental role of CREBBP is reflected by the severe phenotype of homozygous knockout mice, which die in utero with signs of defective blood vessel formation in the central nervous system, developmental retardation, and delays in both primitive and definitive haematopoiesis (Ref. 27). Similarly, homozygous deletion of Ep300 results in mice that die between days 9 and 11.5 of gestation as a result of defects in neurulation, cell proliferation and heart development (Ref. 28). Two additional HATcontaining BRDs have been reported and these interact with EP300 and CREBBP: PCAF [also known as $\mathrm{K}$ (lysine) acetyltransferase 2B (KAT2B)] and the related GCN5. Both proteins acetylate histones and transcription factors, and act as transcriptional coactivators. Gcn5knockout mice die during embryogenesis because of severe growth retardation, failure in the development of dorsal mesoderm lineages and anterior neural tube closure (Refs 29, 30). By contrast, homozygous deletion of the closely related Pcaf gene does not show gross abnormalities, but leads to short-term memory deficits and an exaggerated response to acute stress and conditioned fear, associated with increased plasma corticosterone levels (Ref. 31).

Recent data identified evolutionarily conserved AAA ATPase ANCCA (AAA nuclear coregulator cancer-associated protein)/ATAD2 as a protein required for recruitment of transcription factors of the E2F family to their target sites, and as a transcriptional coregulator of Myc, oestrogen and androgen receptors (ARs). ATAD2 associates through its BRD with histone $\mathrm{H} 3$ acetylated at Lys 14 during late mitosis, regulating the expression of genes required for cell cycle progression (Refs 32, 33, 34).

Dual BRD proteins of the BET (bromodomain and extra-terminal) family also have a pivotal role regulating the transcription of growth-promoting genes and cell cycle regulators. The BET family is represented by four members in humans (BRD2, BRD3, BRD4 and the testis-specific isoform BRDT), with each containing two N-terminal 
Table 1. Bromodomain-containing proteins and their functions

\begin{tabular}{|c|c|c|c|}
\hline Protein & Name & Function & BRDs \\
\hline ASH1L & Absent, small or homeotic-like & Methyltransferase & 1 \\
\hline ATAD2A/B & AAA domain-containing protein 2 & ATPase, coactivator & 1 \\
\hline $\mathrm{BAZ1A} / \mathrm{B}$ & $\begin{array}{l}\mathrm{BRD} \text { adjacent to zinc finger domain } \\
\text { protein } 1 \mathrm{~A}\end{array}$ & $\begin{array}{l}\text { Chromatin assembly and } \\
\text { remodelling }\end{array}$ & 1 \\
\hline $\mathrm{BAZ2A} / \mathrm{B}$ & $\begin{array}{l}B R D \text { adjacent to zinc finger domain } \\
\text { protein } 2 A / B\end{array}$ & Unknown & 1 \\
\hline BRD1 & BRD-containing 1 & Transcription factor & 1 \\
\hline BRD2 & BRD-containing 2 & Transcription factor & 2 \\
\hline BRD3 & BRD-containing 3 & Transcription factor & 2 \\
\hline BRD4 & BRD-containing 4 & Transcription factor & 2 \\
\hline BRDT & BRD-containing protein testis specific & Transcription factor & 2 \\
\hline BRD7 & BRD-containing 7 & Transcriptional repressor & 1 \\
\hline $\mathrm{BRD} 8 \mathrm{~A} / \mathrm{B}$ & BRD-containing 8A/B & TRRAP/TIP60 complex & 2 \\
\hline BRD9 & BRD-containing 9 & Unknown & 1 \\
\hline BRPF1A/B & Peregrin & MOZ complex subunit & 1 \\
\hline BRPF3A & $\begin{array}{l}\text { BRD and PHD-finger-containing } \\
\text { protein } 3\end{array}$ & Unknown & 1 \\
\hline BRWD3 & $\begin{array}{l}\text { BRD and WD-repeat-containing } \\
\text { protein } 3\end{array}$ & JAK/STAT signalling & 2 \\
\hline CECR2 & Cat eye syndrome critical region 2 & Chromatin remodelling & 1 \\
\hline CREBBP & CREB-binding protein & HAT & 1 \\
\hline EP300 & HAT p300 & HAT & 1 \\
\hline FALZ & Fetal Alzheimer antigene & Chromatin remodelling & 1 \\
\hline GCN5L2 & $\begin{array}{l}\text { General control of amino acid synthesis } \\
\text { protein 5-like } 2\end{array}$ & HAT & 1 \\
\hline MLL & Mixed lineage leukaemia & Histone methyltransferase & 1 \\
\hline PB1 & Polybromo & SWI/SNF PBAF subunit & 6 \\
\hline PCAF & P300/CBP-associated factor & HAT & 1 \\
\hline PHIP & $\mathrm{PH}$-interacting protein & Insulin signalling & 2 \\
\hline PRKCBP1 & Protein kinase C-binding protein 1 & Transcriptional regulator & 1 \\
\hline SMARCA2A/B & $\begin{array}{l}\text { SWI/SNF-related, matrix-associated, } \\
\text { actin-dependent regulator of chromatin }\end{array}$ & SWI/SNF ATPase & 1 \\
\hline SMARCA4 & $\begin{array}{l}\text { SWI/SNF-related, matrix-associated, } \\
\text { actin-dependent regulator of chromatin }\end{array}$ & SWI/SNF ATPase & 1 \\
\hline $\begin{array}{l}\text { SP100/SP110/ } \\
\text { SP140 }\end{array}$ & Nuclear body protein & Transcriptional regulator & \\
\hline TAF1/TAF1L & $\begin{array}{l}\text { Transcription initiation TFIID-associated } \\
\text { factor }\end{array}$ & Transcription initiation & 2 \\
\hline $\begin{array}{l}\text { TRIM24/TRIM28/ } \\
\text { TRIM33/TRIM66 }\end{array}$ & Transcription intermediary factor & Transcriptional silencer & 1 \\
\hline WDR9 & $\begin{array}{l}\text { BRD and WD-repeat-containing } \\
\text { protein } 1\end{array}$ & Chromatin remodelling & 2 \\
\hline ZMYND11 & $\begin{array}{l}\text { Zinc finger MYND-domain-containing } \\
\text { protein } 11\end{array}$ & Corepressor & 1 \\
\hline
\end{tabular}

Accession information: doi:10.1017/S1462399411001992; Vol. 13; e29; September 2011 (c) Cambridge University Press 2011. Re-use permitted under a Creative Commons Licence - by-nc-sa. 
BRDs. BRD4 and BRD2 are key mediators of transcriptional elongation by recruiting the positive transcription elongation factor complex (P-TEFb). The P-TEFb core complex is composed of cyclin-dependent kinase-9 (CDK9) and its activator cyclin T. CDK9 phosphorylates the RNA polymerase II (RNAPII) C-terminal domain, a region that contains 52 heptad repeats. RNAPII undergoes sequential phosphorylation at Ser5 during promoter clearance and at Ser2 by P-TEFb at the start of elongation. It has been shown that BRD4 couples $\mathrm{P}-\mathrm{TEFb}$ to acetylated chromatin through its BRDs. Interestingly, in contrast to other BRDcontaining proteins and transcription factors, BET proteins remain associated with condensed and hypoacetylated mitotic chromosomes (Ref. 35), suggesting a role in epigenetic memory (Refs 36, 37). Homeostasis of BET expression levels is important for cell cycle control because both inhibition of BRD4 by microinjected specific antibodies and overexpression of BRD4 lead to cell cycle arrest in the G2M and G1S phases, respectively (Refs 38, 39), and genetic knockdown of BRD4 in cultured human cells significantly reduces cell growth (Ref. 40). BRD2 associates with the E2F transcription factors and with the SWI/SNF (switch mating type/sucrose nonfermenting) complex to regulate the expression of diverse genes (Ref. 41) such as cyclin D1 (CCND1) (Ref. 42). BRD2 can function as a transcriptional coactivator or corepressor in a promoter-specific or tissue-specific manner. Deletion of either BRD2 or BRD4 in mice is lethal, and $\mathrm{Brd}^{+/-}$mice also show severe developmental defects (Refs 43, 44, 45). Mutagenesis of the $\mathrm{Brd} 2$ promoter region resulted in mice that expressed reduced levels of BRD2 without causing gross developmental abnormalities. However, these mice are extremely obese without developing glucose intolerance (Ref. 46). The testis-specific BET family member BRDT is essential for normal spermatogenesis, and specific deletion of the first BRD in mice results in abnormal spermatids and sterility (Ref. 47). In agreement with studies in mice, altered histone modifications have been observed in the BRDT promoter region of subfertile patients (Ref. 48), and genome-wide association studies linked polymorphism in BRDT to sterility in European men (Ref. 49).

Tandem BRDs are also present in TAF1 [RNAPII, TATA box binding protein (TBP)-associated factor,
$250 \mathrm{kDa}$ formerly called TAFII250], the largest subunit of the general transcription factor TFIID. TAF1 binds to the core promoter sequence encompassing the transcriptional start site, and also interacts with other transcriptional regulators, thereby modulating the rate of transcription initiation (Ref. 50). It acts as a general transcriptional activator and as such regulates a variety of essential biological processes, including myogenesis, DNA-damage response, the cell cycle and apoptosis (Refs 51, 52, 53, 54). The C-terminal tandem BRDs have been shown to specifically recognise the diacetylated histone $\mathrm{H} 4$ tail at $\mathrm{K} 5 / \mathrm{K} 12$ or $\mathrm{K} 8 /$ K16, as well as diacetylated P53 at K373/K382 at the p21 promoter (Refs 55, 56). TAF1L is a testis-specific homologue of TAF1. TAF1L is $\mathrm{X}$-linked and might act as a functional substitute for TAF1 during male meiosis, when sex chromosomes are transcriptionally silenced. Similarly to TAF1, TAF1L can bind to the TATAbinding protein (TBP) and can functionally substitute for TAF1 in a temperature-sensitive hamster cell line (Ref. 57).

The WD repeat proteins BRWD1 (WDR9) and BRWD3 also contain tandem BRDs. Members of this family are involved in a variety of cellular processes, including cell cycle progression, signal transduction, apoptosis and gene regulation (Refs 58, 59). Mutations in mice revealed a role for BRWD1 in spermiogenesis and the oocyte-embryo transition (Ref. 60). Despite the specific phenotype in germ-cell maturation, BRWD1 is widely expressed, and its expression levels are dynamic during mouse development. It associates with the SWI/SNF complex component and functions as a transcriptional regulator involved in chromatin remodelling (Ref. 61). Little is known about the biological function of BRWD3. However, in Drosophila, BRWD3 function has been genetically linked to the JAK-STAT pathway (Ref. 62).

Single BRD modules are present in some members of the tripartite motif (TRIM) family of transcriptional regulators (Ref. 63). TRIM proteins are characterised by the presence of a RING finger, one or two zinc-binding motifs named B-boxes, and an associated coiled-coil region (Ref. 64). TRIM24 (Tif1 $\alpha$ ), for instance, contains an N-terminal TRIM domain, a nuclear receptor (LxxLL) interaction motif and a C-terminal PHD-BRD (Ref. 65). TRIM24 associates with chromatin (Ref. 66) and mediates 
ligand-dependent activation of $\mathrm{AR}$ and the retinoic acid receptor (RAR), and has been shown to interact with other nuclear receptors such as thyroid, vitamin $\mathrm{D}_{3}$ and oestrogen receptors (Ref. 67). TRIM28 (TIF1 $\beta$ ) is a corepressor for Krüppel-associated box-domaincontaining zinc finger proteins (Ref. 68), which have a crucial role in early embryogenesis. TRIM28 associates with heterochromatinassociated factors $\mathrm{HP} 1 \alpha, \mathrm{HP} 1 \beta$ and $\mathrm{HP} 1 \gamma$ to promote the silencing of euchromatic genes (Ref. 69), and recruitment of TRIM28 to centromeres is required for induction of the parietal and visceral endoderm differentiation pathways (Refs 70, 71, 72). Interestingly, the PHD domain of the TRIM28 corepressor functions as an intramolecular E3 ligase, leading to sumoylation of the adjacent BRD. Sumoylation is required for TRIM28-mediated gene silencing, suggesting that the tightly linked PHD-BRD module functions as an intramolecular ubiquitin-like modifier (SUMO) E3 ligase (Refs 73, 74).

TRIM33 (Tif1 $\gamma$ ) is a ubiquitin ligase that targets SMAD4 (Ref. 75). Formation of transcription regulatory complexes of SMAD4 with receptorphosphorylated SMAD2 and SMAD3 is a key event in canonical TGF $\beta$ signalling. Consequently, depletion of TRIM33 in human cell lines inhibits SMAD4-dependent cell proliferation by competing with SMAD4 for selective binding to receptor-phosphorylated SMAD2 and SMAD3 (Ref. 76). Mice deficient in Trim33 die in utero, demonstrating that TRIM33 has an important role in development (Ref. 77).

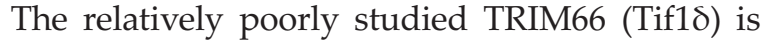
mainly expressed in testis and, similarly to TRIM24/33, associates with heterochromatinassociated factors (HPs) but not with nuclear receptors, and functions as a transcriptional silencer (Ref. 78).

The TRIM family member PML (promyelocytic leukaemia protein TRIM19) has no BRD itself but associates with SP proteins, a family of three proteins in humans (SP100, SP110 and SP140) that all contain a PHD-BRD tandem module N-terminally flanked by a SAND DNA-binding domain. The complex of PML and SP100 is found in nuclear bodies, which are nuclear structures that have been associated with the pathogenesis of acute promyelocytic leukaemia (Ref. 79). Nuclear bodies are implicated in the regulation of many cellular functions, including chromatin organisation (Ref. 80), DNA repair and genome stability (Refs 81, 82), as well as regulation of transcription (Refs 83, 84, 85). In addition, the nuclear body is a target of autoantibodies in patients with primary biliary cirrhosis (Ref. 86) and is involved in viral response (Ref. 87). However, little is known about the precise mechanisms whereby nuclear body proteins exert their functions.

BRDs have an essential role in the assembly and correct targeting of SWI/SNF complexes, which are particularly rich in BRD interaction modules. SWI/SNF complexes, also called Brahmaassociated factors (BAFs), remodel chromatin structure, contributing to either transcriptional activation or repression of target genes, depending on the composition of the various complexes. The components of SWI/SNF complexes were originally identified in screens for mutants that result in defects in mating-type switching in yeast or that were unable to grow on sucrose (Refs 88, 89, 90). Microarray studies later showed that SWI/SNF functions as a transcriptional regulator that affects about $5 \%$ of all genes in yeast (Ref. 91). Mammalian SWI/ SNF complexes have a key role in cell differentiation and proliferation, and represent an essential component of the embryonic stem cell core pluripotency transcriptional network (Refs 92, 93). All SWI/SNF complexes contain a core subunit, which alters chromatin structure in an ATP-dependent manner, resulting in an open and accessible conformation with increased affinity for transcription factors (Ref. 94). In humans, two related SWI/SNF ATPase components are expressed. These two proteins are mutually exclusive in SWI/SNF complexes and have been named after the Drosophila homologue Brahma as BRG1 (Brahma-related gene-1, SMARCA4) and the related protein BRM (SMARCA2). BRG1 and BRM contain a C-terminal BRD that has been implicated in the recognition of acetylated lysines within histone H3 and H4 tails (Ref. 95). Several SWI/SNF complexes have been shown to mediate critical interactions between a number of hormone and other nuclear receptors (Refs 96, 97, 98, 99). In addition, BRG1 has been shown to associate with $\mathrm{Rb}$ proteins, inducing cell cycle arrest and transcriptional repression in an HDACdependent manner. BRG1/HDAC-containing complexes have been shown to repress expression of genes involved in cell cycle

Accession information: doi:10.1017/S1462399411001992; Vol. 13; e29; September 2011 (c) Cambridge University Press 2011. Re-use permitted under a Creative Commons Licence - by-nc-sa. 
regulation (Refs 100, 101). The chromatinremodelling activity of BRG1 has also been shown to be important for traversal of the nucleosome by RNAPII (Ref. 102). The SWI/ SNF complex PBAF (polybromo-associated BRG1-associated factor) is characterised by the presence of the polybromo protein (PB1) (also called BAF180) (Refs 103, 104). PB1 is required for ligand-dependent transactivation by nuclear hormone receptors and contains six BRDs, two bromo-associated domains (BAH) and a homeobox DNA-binding domain. PBAF complexes, but not BAF, activate vitamin-Dreceptor-dependent transcription in response to vitamin $\mathrm{D}$, and mice lacking $\mathrm{Pb} 1$ have defects in heart development (Ref. 105) because of impaired epithelial-to-mesenchymal transition and arrested maturation of the epicardium as a result of the downregulation of FGF, TGF and VEGF signalling (Ref. 106). PB1 also has a role in cell cycle regulation and is a key regulator of senescence (Ref. 107).

BRDs are present in chromatin-remodelling complexes of the ISWI (imitation SWI) family that assemble into at least seven different complexes containing a central core ATPase of the two SNF2-like mammalian homologues SNF2L and SNF2H of yeast ISWI. ISWI complexes are key regulators of transcription, heterochromatin replication and chromatin structure. The ISWI complex NURF (nucleosome remodelling factor) contains the BRD PHD finger transcription factor BPTF. BPTF contains a C-terminal PHD-BRD and was identified as a highly expressed protein in patients with Alzheimer disease as fetal Alz-50 reactive clone 1 , and in fetal brain in patients with neurodegenerative diseases (fetal Alzheimer antigen, FALZ) (Refs 108, 109). The PHD domain in BPTF associates with trimethylated histone H3 Lys4, an interaction that is required for the recruitment of SNF2L1 to promoters (Ref. 110). The ISWI complex ACF/WCRF (ATPutilising chromatin remodelling and assembly factor/Williams syndrome transcription factor) contains BAZ1 (also called WCRF or ACF1), a protein of the BAZ (BRD adjacent zinc finger) family, which is represented by four related genes in humans (BAZ1A, BAZ1B, BAZ2A and BAZ2B), with similar domain organisation, including a PHD-BRD interaction module. BAZ1A was first identified in HeLa cell nuclear extract as a factor associating with $\mathrm{SNF} 2 \mathrm{H}$ forming a complex with ATP-dependent chromatin-remodelling activity (Ref. 111). Later, the SNF2H/BAZ1A remodelling activity was shown to be required for the DNAreplication machinery to penetrate condensed chromatin structures. SNF2H/BAZ1A is particularly enriched in replicating pericentromeric heterochromatin, and knockdown of BAZ1A by RNAi impairs replication of condensed chromatin (Refs 112, 113).

BAZ2A (TIP5, TTF-1-interacting protein 5) is a key subunit of the NoRC (nucleolar remodelling complex), which mediates transcriptional silencing of ribosomal RNA (Ref. 114). Interestingly, mutation of a tyrosine residue in the BAZ2A BRD in yeast impairs interaction with acetylated histones (Ref. 115) and the mutation Y1775F represses NoRC interaction with chromatin and RNA polymerase I transcription (Ref. 116). A table containing all human BRD proteins identified to date and a phylogenetic tree of this protein family is shown in Table 1 and Figure 1a, respectively.

\section{BRD substrates}

Given the central role of BRDs in epigenetic gene regulation, it is surprising that only a few substrates have been reported and mapped to specific sites. Reported affinities range from low micromolar to millimolar $K_{\mathrm{D}}$ values, raising questions regarding the physiological relevance of described weak in vitro substrate interactions, as well as which additional factors contribute to binding specificity (Table 2). BRDs are often associated with other protein-interaction modules, a mechanism that is thought to generate high target selectivity and increased binding affinity with substrates owing to avidity that is generated on simultaneous binding of several interaction domains. This property led to the suggestion that epigenetic regulation recognises patterns of post-translational modifications (words) rather than single modifications (letters) (Ref. 130). In addition, the reading process might require combinations of several modifications for high-affinity interaction with a single BRD. Recently, Moriniere and coworkers showed that the testisspecific BET isoform BRDT requires the presence of several acetylation sites for high-affinity binding to histone tails (Ref. 118). Interestingly, both acetylated lysines interact with the same binding pocket in BRDT (Fig. 1b). It is also 
Figure 1. Phylogenetic tree of the human bromodomain family and substrate recognition of bromodomains. (a) Phylogenetic tree based on sequence alignments of predicted BRDs. For targets with multiple BRDs, the domains have been numbered starting from the $\mathrm{N}$-terminus and the number is shown in parentheses. (b) Interaction of mouse BRD4 (Ref. 117) and mouse BRDT (Ref. 118) with monoacetylated Lys14 in histone $\mathrm{H} 3$ and a diacetylated H4 peptide monoacetylated on both Lys5 and Lys8. (c) Surface representation in similar orientation. See Table 1 for an explanation of protein symbols.

likely that other post-translational modifications, such as phosphorylation and methylation, influence substrate recognition, providing the basis for crosstalk of transcription control and cellular signalling. Similarly, the related BRD protein BRD3 also requires two adjacent acetylation sites for tight interaction with the transcription factor GATA1 (Ref. 131).

\section{BRDs as therapeutic targets in cancer}

Many proteins that use BRDs for their recruitment to specific regulatory complexes have been implicated in the development of cancer. BRDcontaining proteins are usually multicomponent, and often the reported disease association has not been directly linked to defects in the BRD module itself. However, a number of dominant oncogenic rearrangements and correlation of overexpression of BRD proteins with patient survival provide a strong case for targeting BRDs in cancer.

Genetic rearrangements of BRD-containing proteins have been linked to the development of a number of extremely aggressive tumours. A very aggressive poorly differentiated carcinoma that originates mainly from midline locations such as the head, neck or mediastinum is NUT (nuclear protein in testis) midline carcinoma (NMC) (Ref. 132). NMCs are genetically characterised by translocations that involve the NUT protein with BRD4, BRD3 or an unknown partner gene. BRD4-NUT rearrangements are

Accession information: doi:10.1017/S1462399411001992; Vol. 13; e29; September 2011 (c) Cambridge University Press 2011. Re-use permitted under a Creative Commons Licence - by-nc-sa. 
Accession information: doi:10.1017/S1462399411001992; Vol. 13; e29; September 2011

(C) Cambridge University Press 2011. Re-use permitted under a Creative Commons Licence - by-nc-sa. 
Figure 2. Domain organisation of bromodomain proteins and translocations in cancer. BRD modules are shown in green (labelled BRD). Other domain types are labelled directly in the figure and breakpoints are indicated by arrows. Wild-type domain arrangements are shown in the upper panel. See Table 1 for an explanation of protein symbols.

most frequent, occurring in two-thirds of cases. Both BRD4-NUT and BRD3-NUT fusion genes encode proteins composed of the N-terminal tandem BRDs and almost the entire NUT gene (Fig. 2). BRD-NUT blocks cellular differentiation, and depletion of this oncogene by RNAi results in squamous differentiation and cell cycle arrest (Refs 133, 134). BRD4-NUT specifically recruits $\mathrm{CBP} / \mathrm{p} 300$, leading to stimulation of $\mathrm{CBP} / \mathrm{p} 300$ HAT activity, formation of nuclear foci and inactivation of p53 (Ref. 135). Selective inhibition of BRD4-NUT by recently developed acetyl lysine competitive inhibitors results in epithelial differentiation, tumour shrinkage and survival in BRD4-NUT xenograft mice (Ref. 136).

Chromosomal translocations of CREBBP with the MLL protein and the monocytic leukaemia zinc finger protein (MOZ) have been described in myeloid and lymphoid acute leukaemia and myelodysplasia secondary to therapy with drugs targeting DNA topoisomerase II (Refs 137, 138) (Fig. 2). CREBBP also contributes to tumourigenesis of NUP98-HoxA9 and MOZ-TIF2 fusion proteins by activating transcription (Refs 139, 140). In addition, CREBBP mutations have been identified in relapsed acute lymphoblastic leukaemia (Ref. 140) and are very common in diffuse large B-cell lymphoma and follicular lymphoma, constituting the major pathogenetic mechanism shared by common forms of B-cell nonHodgkin's lymphoma (Ref. 141). CREBBP and the related HAT EP300 are also highly expressed in advanced prostate cancer, and expression

Accession information: doi:10.1017/S1462399411001992; Vol. 13; e29; September 2011 (c) Cambridge University Press 2011. Re-use permitted under a Creative Commons Licence - by-nc-sa. 
levels have been linked with cancer patient survival (Ref. 142).

Overexpression of several BRD proteins has been reported in cancer and has been linked to patient survival. For instance, a recent study showed that ATAD2 is overexpressed in more than $70 \%$ of breast tumours and that higher protein levels correlate with tumour histological grades, poor overall survival and disease recurrence (Ref. 33). Revenko and coworkers showed that ATAD2 is required for recruitment of specific E2F transcription factors and for chromatin assembly of the host cell factor 1-MLL histone methyltransferase complex. As a result of its association with the MLL methyltransferase, depletion of ATAD2 results in a marked decrease of trimethylation of Lys4 in histone H3, which has been linked to transcriptional activation. BRD mutations disable ATAD2 function as an E2F coactivator and its ability to promote cancer cell proliferation (Ref. 32). The closely related protein ATAD2B has recently been shown to be highly expressed in glioblastoma and oligodendroglioma, as well as in breast carcinoma (Ref. 143).

Aberrant expression has also been reported for TRIM24 in breast cancer, and high expression levels have been shown to negatively correlate with survival of breast cancer patients (Ref. 129). In liver, however, TRIM24 seems to function as a liver-specific tumour suppressor (Ref. 144). TRIM24 also interacts with AR and enhances transcriptional activity of the AR by dihydrotestosterone in prostate cancer cells (Ref. 145). These data suggest that TRIM24 function and its role in tumourigenesis might be highly context dependent.

The testis-specific BET family member BRDT is frequently overexpressed in non-small-cell lung cancer (Ref. 146) and several other cancers (Ref. 147), but the functional consequences of BRDT overexpression have not been investigated so far. The role of BRD4 in cancer is better understood. BRD4 has been shown to be a key regulator of cell cycle control and transcriptional elongation of growth-promoting genes. In particular, the key role of BRD4 in the recruitment of P-TEFb (CDK9/cyclinT) to transcriptional start sites provides an alternative strategy to targeting CDK9, which emerged as a validated target in chronic lymphocytic leukaemia (Ref. 148). In breast cancer, however,
BRD4 has been identified as an inherited susceptibility gene for disease progression and its expression levels have been associated with patient survival (Ref. 149). BRD4 and BRD2 also have a key role for the transmission of tumour viruses during mitosis by providing a chromatin anchor to viral episomes. For instance, during latent viral infection of herpes viruses associated with development of Kaposi sarcoma, the transmission of viral genomes to daughter cells during mitosis is mediated by the episome's latency-associated nuclear antigen 1, which is tethered to chromatin through its interaction with BRD4 (Ref. 150). Also, papilloma viruses that have been linked to the development of cervical cancers and Epstein-Barr viruses associate with BRD4 in order to anchor their viral genomes to mitotic chromosomes (Refs 151, 152).

\section{BRDs as therapeutic targets for the treatment of inflammation}

Transcriptional control of proinflammatory cytokines is the central mechanism in the aetiology of inflammatory disease, and given the success of HDAC inhibitors in this area, it is likely that selective BRD inhibitors will modulate these processes. A first example has been provided by the recent pan-BET inhibitor iBET, which leads to the disruption of chromatin complexes responsible for the expression of inflammatory genes and conferred protection against lipopolysaccharide-induced endotoxic shock and bacteria-induced sepsis (Ref. 153). Three sites of polymorphism in BRD2 have recently been linked to rheumatoid arthritis (Ref. 154) and Brd2-hypomorphic mice are severely obese and have reduced inflammation in fat tissue (Ref. 46).

The BRD-containing HATs EP300/CREBBP have been proposed as therapeutic targets in inflammatory diseases such as lung inflammation and asthma (Ref. 155). Activation of proinflammatory genes is intimately linked to activation of nuclear factor $\kappa \mathrm{B}(\mathrm{NF} \kappa \mathrm{B})$. The activated p65 subunit translocates to the nucleus, where its affinity to its target genes and transcriptional activity is regulated by acetylation by EP300/CREBBP. Compounds that inhibit NFkB acetylation such as the natural product gallic acid have anti-inflammatory properties (Refs 156, 157). EP300 and PCAF also regulate inflammatory responses through their 
regulation of cyclooxygenase-2 (COX2) expression. COX2 is a key enzyme of prostaglandin biosynthesis that is well established as a major player in inflammatory response and a clinically successful target for the development of anti-inflammatory drugs. Stimulation by bacterial lipopolysaccharides and other cytokines leads to increased binding of PCAF and EP300 to the COX2 promoter, and its activation. Conversely, inhibitors of EP300 have been shown to reduce COX2 protein levels and promoter activities (Ref. 158).

The concerted activation of several proinflammatory genes is regulated by the SWI/ SNF class of ATP-dependent remodelling complexes, which make the promoters of inflammatory genes permissive for transcriptional induction. The presence of the catalytic ATPase subunit BRG1 at the promoter of proinflammatory genes such as IL6 has been shown to be necessary for activation of these genes, and termination of transcriptional activation is regulated by proteasomal degradation of BRG1, ensuring a timely and adequate immune response (Ref. 159). Although experimental data are still missing, it is intriguing to speculate that removal of BRG1 from promoter regions might have an effect on inflammatory conditions.

\section{BRDs as therapeutic targets for the treatment of neurological diseases}

Increasing evidence points to the fact that epigenetic targets have a role in the molecular manifestation of stress and related disorders. Because BRD inhibitors have only just been discovered, no study has addressed the role of BRD inhibition in neurological disorders so far. However, several studies report important functions of BRD-containing proteins in several diseases. TRIM28, for instance, is highly expressed in the mouse hippocampus and cerebellum. Inducible deletion of Trim 28 in the forebrain of adult mice resulted in stress-related behaviour and cognitive impairment of these mice similar to effects observed in behavioural disorders such as borderline personality or bipolar disorder. Chromatin immunoprecipitation experiments confirmed changes in histone methylation and acetylation patterns in the promoter regions of TRIM28 target genes such as Mkrn3 and Pcdhb6 (Refs 160, 161).
Two other BRD-containing proteins, SMARCA2 (BRM) and BRD1, have been identified in genomewide association studies as susceptibility genes for schizophrenia and bipolar disorder in several independent studies, but the molecular mechanisms are still unclear (Refs 162, 163). In addition, low levels of SMARCA2 have been found in the post-mortem prefrontal brains of schizophrenic patients, and the gene expression profiles in the diseased brains match those after downregulation of SMARCA2 in cells and in SMARCA2-knockout mice, which show impaired social interaction and prepulse inhibition. Interestingly, SMARCA2 expression can be increased in the mouse brain on application of antipsychotic drugs, providing further evidence of the potential of this protein as a target for the treatment of schizophrenia (Refs 164, 165).

Mutations in CREBBP, and less frequently in EP300, are the genetic background for Rubinstein-Taybi syndrome (RTS), a rare human genetic disorder characterised by mental retardation and physical abnormalities; many patients with RTS have either breakpoints or microdeletions in chromosome 16p13.3 where the CREBBP gene is located, but also heterozygous point mutations can lead to RTS (Refs 166, 167, 168). Several of the pathological features can be mirrored by heterozygous Crebbp-deficient mice strains (Refs 169, 170, 171). Although the precise mechanisms underlying the disease are not yet understood, it is thought that the HAT activity of CREBBP and reduced transcriptional activity result in altered synaptic plasticity, which ultimately influences long-term memory, leading to mental retardation (Ref. 172). EP300 also has a role in the aetiology of amyotrophic lateral sclerosis, Alzheimer disease and Huntington disease. Huntington disease is a polyQ disease in which polyglutamine repeats are added to the Huntingtin protein, causing its translocation to the nucleus and formation of aggregates. CREBBP and PCAF interact directly with Huntingtin aggregates, resulting in their depletion (Refs 173, 174). Indeed, HDAC inhibitors have long been used as mood stabilisers and are studied for the treatment of Huntington and Alzheimer diseases (Ref. 175).

\section{Development of BRD inhibitors}

BRDs share a conserved fold that comprises a lefthanded bundle of four alpha helices $\left(\alpha_{\mathrm{Z}}, \alpha_{\mathrm{A}}, \alpha_{\mathrm{B}}\right.$,

Accession information: doi:10.1017/S1462399411001992; Vol. 13; e29; September 2011

(C) Cambridge University Press 2011. Re-use permitted under a Creative Commons Licence - by-nc-sa. 
Figure 3. Structural overview of a bromodomain and binding mode of bromodomain inhibitors. (a) Ribbon diagram of the first BRD of BRD4. The main structural elements as well as the acetyl lysine binding site residues are labelled. (b) Superimposition of a diacetylated BET substrate peptide and the inhibitor JQ1. Inhibitor and peptide molecules are shown in stick representation and are coloured according to atom types. (c) Binding of JQ1 to the bromodomain of BRD4. Conserved water molecules in the active site are highlighted and hydrogen bonds are shown as dashed lines. (d) Complex of ischemin with CREBBP (Ref. 176).

$\alpha_{\mathrm{C}}$ ), linked by highly variable loop regions (ZA and $\mathrm{BC}$ loops), which form the rim of the substratebinding pocket and determine substrate recognition (Refs 55, 127) (Fig. 3a). Despite the conservation of the overall BRD fold, the surface and loop regions of BRDs are highly diverse, suggesting that inhibitors with high specificity can be designed. Cocrystal structures with peptidic substrates have demonstrated that the acetyl lysine is recognised by a central deep hydrophobic cavity, where it is anchored by a hydrogen bond to an asparagine residue present in most BRDs (Ref. 177). Acetylation of lysine residues neutralises the charge of the $\varepsilon$-amino group. As a consequence, the central cavity of acetyl lysine binding sites in BRDs is quite hydrophobic and particularly rich in aromatic residues; it also has sufficient size to accommodate potent acetyl lysine competitive ligands. These properties make BRDs attractive targets for the design of pharmacologically active molecules that compete with protein interactions mediated by thesemodules.

Accession information: doi:10.1017/S1462399411001992; Vol. 13; e29; September 2011 (c) Cambridge University Press 2011. Re-use permitted under a Creative Commons Licence - by-nc-sa. 
<smiles>Cc1sc2c(c1C)C(c1ccc(Cl)cc1)=N[C@@H](CC(=O)C(C)(C)C)c1nnc(C)n1-2</smiles>

(+)-JQ1

pan-BET

$\mathrm{K}_{\mathrm{D}}: 60 \mathrm{nM}(\mathrm{BRD} 4)$<smiles>CCOC(=O)C[C@@H]1N=C(c2ccc(Cl)cc2)c2cc(OC)ccc2-n2c(C)nnc21</smiles>

iBET

pan-BET

$\mathrm{K}_{\mathrm{D}}: 50 \mathrm{nM}(\mathrm{BRD} 4)$<smiles>Cc1nnc2n1-c1ccccc1C(c1ccccc1)=N[C@H]2NC(=O)OCc1ccccc1</smiles><smiles>Cc1cc(N=Nc2cc(S(=O)(=O)O)c(C)cc2C)c(N)cc1O</smiles>

Ischemin $\mathrm{K}_{\mathrm{D}}: 19 \mu \mathrm{m}$ (CREBBP)
pan-BET

$\mathrm{K}_{\mathrm{D}}: 19-80 \mathrm{nM}$

(Tandem BET-BRDs)

\section{Chemical structures of bromodomain inhibitors}

Expert Reviews in Molecular Medicine (c) 2011 Cambridge University Press

Figure 4. Chemical structures of bromodomain inhibitors. Specificity and dissociation constants are also indicated.

Potent and very selective inhibitors have recently been published for BET BRDs (Refs 136, 153, 178). All inhibitors that have been published so far are based on a triazolodiazepine scaffold that successfully mimics interactions observed in BET peptide complexes (Fig. 3b). Interestingly, a number of tightly bound and conserved water molecules remain in cocrystal structures of BET triazolo-diazepine complexes, which interact with the inhibitor through a network of hydrogen bonds (Fig. 3c). Two BET inhibitors have been studied in two different disease models, providing compelling support of BET BRDs as targets in drug discovery. The inhibitor JQ1 has been studied in midline carcinoma where inhibition of BRD4-NUT led to terminal differentiation, cell cycle arrest and apoptosis of carcinoma cells, and significant reduction of tumour growth in patient-cell-line-derived xenograft models (Ref. 136). The inhibitor iBET led to significant reduction of the expression of proinflammatory genes in activated macrophages, and conferred protection against lipopolysaccharide-induced endotoxic shock and bacteria-induced sepsis, supporting inhibition of BET BRDs as a strategy for the generation of immunomodulatory drugs (Ref. 153).

Acetyl lysine mimetic inhibitors have also been reported in the case of CREBBP, competing for its interaction with p53. These inhibitors were identified by NMR screening using a library of compounds that consists of one aromatic ring connected to an $-\mathrm{NHCOCH}_{3}$ group by different types of linkers (Ref. 179). The same laboratory also reported a series of cyclic peptides with improved binding affinities over natural substrates (Ref. 179) and azobenzene-based inhibitors such as 4-hydroxyphenylazobenzenesulfonic acid (MS456) and ischemin. Ischemin binds to the BRDs of CREBBP with a dissociation constant $\left(K_{\mathrm{D}}\right)$ of $19 \mu \mathrm{M}$ and shows at least fivefold selectivity over other human BRDs. The binding mode of ischemin in CREBBP is shown in Figure 3d. In cellular assays ischemin alters post-translational modifications of p53 and histones, inhibits p53 interaction with CBP and transcriptional activity in cells, and prevents apoptosis in ischaemic cardiomyocytes (Ref. 179). Early lead compounds such as N1-aryl-propane-1,3diamine have also been identified for PCAF (Ref. 180). A summary of the chemical structures of the currently most advanced BRD inhibitors is shown in Figure 4.

\section{Research in progress and outstanding research questions}

Targeting BRDs for the development of proteininteraction inhibitors has recently emerged as a strategy for the design of pharmacologically active reagents. The relatively weak interaction 
of BRDs with their substrates, the diversity and physicochemical properties of the acetyl lysine binding site, and the large number of available crystal structures will facilitate the rational design of such inhibitors. However, BRDs usually constitute only one of the interaction domains found in BRD-containing proteins, and whether selective inhibition of the acetyl lysine interaction alone will result in the desired phenotype needs to be investigated in future research projects. The large number of diseases that have been linked to BRD-containing proteins and the success of particular HDAC inhibitors indicate that BRD inhibitors will find a large number of applications in pharmaceutical sciences and basic research.

\section{Acknowledgements}

We thank the referees for their detailed and constructive criticism. The Structural Genomics Consortium is a registered charity (number 1097737) that receives funds from the Canadian Institutes for Health Research, the Canadian Foundation for Innovation, Genome Canada through the Ontario Genomics Institute, GlaxoSmithKline, Karolinska Institutet, the Knut and Alice Wallenberg Foundation, the Ontario Innovation Trust, the Ontario Ministry for Research and Innovation, Merck \& Co., Inc., the Novartis Research Foundation, the Swedish Agency for Innovation Systems, the Swedish Foundation for Strategic Research and the Wellcome Trust. We apologise for research that we were not able to cite as a result of space constraints.

\section{References}

1 Kouzarides, T. (2000) Acetylation: a regulatory modification to rival phosphorylation? EMBO Journal 19, 1176-1179

2 Choudhary, C. et al. (2009) Lysine acetylation targets protein complexes and co-regulates major cellular functions. Science 325, 834-840

3 Shogren-Knaak, M. et al. (2006) Histone H4-K16 acetylation controls chromatin structure and protein interactions. Science 311, 844-847

4 Kouzarides, T. (2007) Chromatin modifications and their function. Cell 128, 693-705

5 Guan, K.L. and Xiong, Y. (2011) Regulation of intermediary metabolism by protein acetylation. Trends in Biochemical Sciences 36, $108-116$
6 Celic, I. et al. (2006) The sirtuins hst3 and Hst4p preserve genome integrity by controlling histone $\mathrm{h} 3$ lysine 56 deacetylation. Current Biology 16, 1280-1289

7 Bertrand, P. (2010) Inside HDAC with HDAC inhibitors. European Journal of Medicinal Chemistry 45, 2095-2116

8 Bowers, E.M. et al. (2010) Virtual ligand screening of the p300/CBP histone acetyltransferase: identification of a selective small molecule inhibitor. Chemistry and Biology 17, 471-482

9 Mujtaba, S., Zeng, L. and Zhou, M.M. (2007) Structure and acetyl-lysine recognition of the bromodomain. Oncogene 26, 5521-5527

10 Vollmuth, F. and Geyer, M. (2010) Interaction of propionylated and butyrylated histone $\mathrm{H} 3$ lysine marks with Brd4 bromodomains. Angewandte Chemie International Edition in English 49, 6768-6772

11 Tamkun, J.W. et al. (1992) brahma: a regulator of Drosophila homeotic genes structurally related to the yeast transcriptional activator SNF2/SWI2. Cell $68,561-572$

12 Haynes, S.R. et al. (1992) The bromodomain: a conserved sequence found in human, Drosophila and yeast proteins. Nucleic Acids Research 20, 2603

13 Nagy, Z. and Tora, L. (2007) Distinct GCN5/PCAFcontaining complexes function as co-activators and are involved in transcription factor and global histone acetylation. Oncogene 26, 5341-5357

14 Trotter, K.W. and Archer, T.K. (2008) The BRG1 transcriptional coregulator. Nuclear Receptor Signaling 6, 004

15 Malik, S. and Bhaumik, S.R. (2010) Mixed lineage leukemia: histone H3 lysine 4 methyltransferases from yeast to human. FEBS Journal 277, 1805-1821

16 Gregory, G.D. et al. (2007) Mammalian ASH1L is a histone methyltransferase that occupies the transcribed region of active genes. Molecular and Cellular Biology 27, 8466-8479

17 Bres, V., Yoh, S.M. and Jones, K.A. (2008) The multitasking P-TEFb complex. Current Opinion in Cell Biology 20, 334-340

18 Venturini, L. et al. (1999) TIF1gamma, a novel member of the transcriptional intermediary factor 1 family. Oncogene 18, 1209-1217

19 Jacobson, R.H. et al. (2000) Structure and function of a human TAF(II)250 double bromodomain module. Science 288, 1422-1425

20 Nakamura, T. et al. (2000) huASH1 protein, a putative transcription factor encoded by a human

Accession information: doi:10.1017/S1462399411001992; Vol. 13; e29; September 2011 (c) Cambridge University Press 2011. Re-use permitted under a Creative Commons Licence - by-nc-sa. 
homologue of the Drosophila ash1 gene, localizes to both nuclei and cell-cell tight junctions.

Proceedings of the National Academy of Sciences of the United States of America 97, 7284-7289

21 Mohan, M. et al. (2010) Licensed to elongate: a molecular mechanism for MLL-based leukaemogenesis. Nature Reviews. Cancer 10, 721-728

$22 \mathrm{Yu}$, B.D. et al. (1995) Altered Hox expression and segmental identity in Mll-mutant mice. Nature 378, 505-508

23 Yagi, H. et al. (1998) Growth disturbance in fetal liver hematopoiesis of Mll-mutant mice. Blood 92, 108-117

24 McMahon, K.A. et al. (2007) Mll has a critical role in fetal and adult hematopoietic stem cell selfrenewal. Cell Stem Cell 1, 338-345

25 Radhakrishnan, I. et al. (1997) Solution structure of the KIX domain of CBP bound to the transactivation domain of CREB: a model for activator:coactivator interactions. Cell 91, 741-752

26 Kalkhoven, E. (2004) CBP and p300: HATs for different occasions. Biochemical Pharmacology 68, 1145-1155

27 Tanaka, Y. et al. (2000) Extensive brain hemorrhage and embryonic lethality in a mouse null mutant of CREB-binding protein. Mechanisms of Development 95, 133-145

28 Yao, T.P. et al. (1998) Gene dosage-dependent embryonic development and proliferation defects in mice lacking the transcriptional integrator p300. Cell 93, 361-372

$29 \mathrm{Bu}$, P. et al. (2007) Loss of Gcn5 acetyltransferase activity leads to neural tube closure defects and exencephaly in mouse embryos. Molecular and Cellular Biology 27, 3405-3416

$30 \mathrm{Xu}, \mathrm{W}$. et al. (2000) Loss of Gcn5l2 leads to increased apoptosis and mesodermal defects during mouse development. Nature Genetics 26, 229-232

31 Maurice, T. et al. (2008) Altered memory capacities and response to stress in p300/CBP-associated factor (PCAF) histone acetylase knockout mice. Neuropsychopharmacology 33, 1584-1602

32 Revenko, A.S. et al. (2010) Chromatin loading of E2F-MLL complex by cancer-associated coregulator ANCCA via reading a specific histone mark. Molecular and Cellular Biology 30, 5260-5272

33 Ciro, M. et al. (2009) ATAD2 is a novel cofactor for MYC, overexpressed and amplified in aggressive tumors. Cancer Research 69, 8491-8498

34 Zou, J.X. et al. (2007) ANCCA, an estrogenregulated AAA + ATPase coactivator for ERalpha, is required for coregulator occupancy and chromatin modification. Proceedings of the National Academy of Sciences of the United States of America 104, 18067-18072

35 Dey, A. et al. (2000) A bromodomain protein, MCAP, associates with mitotic chromosomes and affects G(2)-to-M transition. Molecular and Cellular Biology 20, 6537-6549

36 Kanno, T. et al. (2004) Selective recognition of acetylated histones by bromodomain proteins visualized in living cells. Molecular Cell 13, 33-43

37 Dey, A. et al. (2003) The double bromodomain protein Brd4 binds to acetylated chromatin during interphase and mitosis. Proceedings of the National Academy of Sciences of the United States of America 100, 8758-8763

38 Dey, A. et al. (2000) A bromodomain protein, MCAP, associates with mitotic chromosomes and effects, G(2)-to-M transition. Molecular and Cellular Biology 20, 6537-6549

39 Maruyama, T. et al. (2002) A mammalian bromodomain protein, Brd4, interacts with replication factor $C$ and inhibits progression to $S$ phase. Molecular and Cellular Biology 22, 6509-6520

$40 \mathrm{Wu}$, S.Y. et al. (2006) Brd4 links chromatin targeting to HPV transcriptional silencing. Genes and Development 20, 2383-2396

41 Denis, G.V. et al. (2006) Identification of transcription complexes that contain the double bromodomain protein Brd2 and chromatin remodeling machines. Journal of Proteome Research 5, 502-511

42 Leroy, G., Rickards, B. and Flint, S.J. (2008) The double bromodomain proteins Brd2 and Brd3 couple histone acetylation to transcription. Molecular Cell 30, 51-60

43 Houzelstein, D. et al. (2002) Growth and early postimplantation defects in mice deficient for the bromodomain-containing protein Brd4. Molecular and Cellular Biology 22, 3794-3802

44 Shang, E. et al. (2009) Double bromodomaincontaining gene $\mathrm{Brd} 2$ is essential for embryonic development in mouse. Developmental Dynamics 238, 908-917

45 Gyuris, A. et al. (2009) The chromatin-targeting protein Brd2 is required for neural tube closure and embryogenesis. Biochimica Biophysica et Acta $1789,413-421$

46 Wang, F. et al. (2010) Brd2 disruption in mice causes severe obesity without Type 2 diabetes. Biochemical Journal 425, 71-83 
47 Shang, E. et al. (2007) The first bromodomain of Brdt, a testis-specific member of the BET sub-family of double-bromodomain-containing proteins, is essential for male germ cell differentiation. Development 134, 3507-3515

48 Steilmann, C. et al. (2010) The interaction of modified histones with the bromodomain testisspecific (BRDT) gene and its mRNA level in sperm of fertile donors and subfertile men. Reproduction $140,435-443$

49 Aston, K.I. et al. (2010) Evaluation of 172 candidate polymorphisms for association with

oligozoospermia or azoospermia in a large cohort of men of European descent. Human Reproduction 25, 1383-1397

50 Wassarman, D.A. and Sauer, F. (2001) TAF(II)250: a transcription toolbox. Journal of Cell Science 114, 2895-2902

51 Deato, M.D. and Tjian, R. (2007) Switching of the core transcription machinery during myogenesis. Genes and Development 21, 2137-2149

52 Buchmann, A.M., Skaar, J.R. and DeCaprio, J.A. (2004) Activation of a DNA damage checkpoint response in a TAF1-defective cell line. Molecular and Cellular Biology 24, 5332-5339

53 Lin, C.Y. et al. (2002) The cell cycle regulatory factor TAF1 stimulates ribosomal DNA transcription by binding to the activator UBF. Current Biology 12, 2142-2146

54 Kimura, J. et al. (2008) A functional genome-wide RNAi screen identifies TAF1 as a regulator for apoptosis in response to genotoxic stress. Nucleic Acids Research 36, 5250-5259

55 Jacobson, R.H. et al. (2000) Structure and function of a human TAFII250 double bromodomain module. Science 288, 1422-1425

56 Li, A.G. et al. (2007) An acetylation switch in p53 mediates holo-TFIID recruitment. Molecular Cell 28, 408-421

57 Wang, P.J. and Page, D.C. (2002) Functional substitution for TAF(II)250 by a retroposed homolog that is expressed in human spermatogenesis. Human Molecular Genetics 11, 2341-2346

58 Kalla, C. et al. (2005) Translocation t(X;11)(q13;q23) in B-cell chronic lymphocytic leukemia disrupts two novel genes. Genes, Chromosomes and Cancer 42, 128-143

59 Ramos, V.C. et al. (2002) Characterisation and expression analysis of the WDR9 gene, located in the Down critical region- 2 of the human chromosome 21. Biochimica Biophysica et Acta $1577,377-383$

60 Philipps, D.L. et al. (2008) The dual bromodomain and WD repeat-containing mouse protein BRWD1 is required for normal spermiogenesis and the oocyte-embryo transition. Developmental Biology $317,72-82$

61 Huang, H. et al. (2003) Expression of the Wdr9 gene and protein products during mouse development. Developmental Dynamics 227, 608-614

62 Muller, P. et al. (2005) Identification of JAK/STAT signalling components by genome-wide RNA interference. Nature 436, 871-875

63 Borden, K.L. (2000) RING domains: master builders of molecular scaffolds? Journal of Molecular Biology 295, 1103-1112

64 Meroni, G. and Diez-Roux, G. (2005) TRIM/RBCC, a novel class of 'single protein RING finger' E3 ubiquitin ligases. Bioessays 27, 1147-1157

65 Peng, H., Feldman, I. and Rauscher, F.J., 3rd (2002) Hetero-oligomerization among the TIF family of RBCC/TRIM domain-containing nuclear cofactors: a potential mechanism for regulating the switch between coactivation and corepression. Journal of Molecular Biology 320, 629-644

66 Remboutsika, E. et al. (1999) The putative nuclear receptor mediator TIF1alpha is tightly associated with euchromatin. Journal of Cell Science $112(\mathrm{Pt}$ 11), 1671-1683

67 Le Douarin, B. et al. (1996) A possible involvement of TIF1 alpha and TIF1 beta in the epigenetic control of transcription by nuclear receptors. EMBO Journal 15, 6701-6715

68 Friedman, J.R. et al. (1996)KAP-1, a novel corepressor for the highly conserved KRAB repression domain. Genes and Development 10, 2067-2078

69 Cammas, F. et al. (2002) Cell differentiation induces TIF1beta association with centromeric heterochromatin via an HP1 interaction. Journal of Cell Science 115, 3439-3448

70 Li, Y., Kirschmann, D.A. and Wallrath, L.L. (2002) Does heterochromatin protein 1 always follow code? Proceedings of the National Academy of Sciences of the United States of America 99 (Suppl 4), 16462-16469

71 Bartova, E. et al. (2007) Differentiation-specific association of HP1alpha and HP1beta with chromocentres is correlated with clustering of TIF1beta at these sites. Histochemistry and Cell Biology 127, 375-388

72 Cammas, F. et al. (2004) Association of the transcriptional corepressor TIF1beta with heterochromatin protein 1 (HP1): an essential role 
for progression through differentiation. Genes and Development 18, 2147-2160

73 Ivanov, A.V. et al. (2007) PHD domain-mediated E3 ligase activity directs intramolecular sumoylation of an adjacent bromodomain required for gene silencing. Molecular Cell 28, 823-837

74 Zeng, L. et al. (2008) Structural insights into human KAP1 PHD finger-bromodomain and its role in gene silencing. Nature Structural and Molecular Biology 15, 626-633

75 Dupont, S. et al. (2005) Germ-layer specification and control of cell growth by Ectodermin, a Smad4 ubiquitin ligase. Cell 121, 87-99

$76 \mathrm{He}, \mathrm{W}$. et al. (2006) Hematopoiesis controlled by distinct TIF1gamma and Smad4 branches of the TGFbeta pathway. Cell 125, 929-941

77 Kim, J. and Kaartinen, V. (2008) Generation of mice with a conditional allele for Trim33. Genesis 46, 329-333

78 Khetchoumian, K. et al. (2004) TIF1delta, a novel HP1-interacting member of the transcriptional intermediary factor 1 (TIF1) family expressed by elongating spermatids. Journal of Biological Chemistry 279, 48329-48341

79 Bernardi, R. and Pandolfi, P.P. (2007) Structure, dynamics and functions of promyelocytic leukaemia nuclear bodies. Nature Reviews. Molecular Cell Biology 8, 1006-1016

80 Boisvert, F.M. et al. (2001) The transcription coactivator CBP is a dynamic component of the promyelocytic leukemia nuclear body. Journal of Cell Biology 152, 1099-1106

81 Dellaire, G. et al. (2006) Promyelocytic leukemia nuclear bodies behave as DNA damage sensors whose response to DNA double-strand breaks is regulated by NBS1 and the kinases ATM, Chk2, and ATR. Journal of Cell Biology 175, 55-66

82 Zhong, S. et al. (1999) A role for PML and the nuclear body in genomic stability. Oncogene 18, 7941-7947

83 Boisvert, F.M., Hendzel, M.J. and Bazett-Jones, D.P. (2000) Promyelocytic leukemia (PML) nuclear bodies are protein structures that do not accumulate RNA. Journal of Cell Biology 148, 283-292

84 Wang, J. et al. (2004) Promyelocytic leukemia nuclear bodies associate with transcriptionally active genomic regions. Journal of Cell Biology 164, 515-526

85 Wu, W.S. et al. (2001) The growth suppressor PML represses transcription by functionally and physically interacting with histone deacetylases. Molecular and Cellular Biology 21, 2259-2268
86 Stinton, L.M. et al. (2011) Autoantibodies to GW bodies and other autoantigens in primary biliary cirrhosis. Clinical and Experimental Immunology 163, 147-156

87 Ishov, A.M. and Maul, G.G. (1996) The periphery of nuclear domain 10 (ND10) as site of DNA virus deposition. Journal of Cell Biology 134, $815-826$

88 Neigeborn, L. and Carlson, M. (1984) Genes affecting the regulation of SUC2 gene expression by glucose repression in Saccharomyces cerevisiae. Genetics 108, 845-858

89 Stern, M., Jensen, R. and Herskowitz, I. (1984) Five SWI genes are required for expression of the $\mathrm{HO}$ gene in yeast. Journal of Molecular Biology 178, 853-868

90 Winston, F. and Carlson, M. (1992) Yeast SNF/SWI transcriptional activators and the SPT/SIN chromatin connection. Trends in Genetics 8, 387-391

91 Sudarsanam, P. et al. (2000) Whole-genome expression analysis of snf/swi mutants of Saccharomyces cerevisiae. Proceedings of the National Academy of Sciences of the United States of America 97, 3364-3369

92 Ho, L. et al. (2009) An embryonic stem cell chromatin remodeling complex, esBAF, is an essential component of the core pluripotency transcriptional network. Proceedings of the National Academy of Sciences of the United States of America 106, 5187-5191

93 Singhal, N. et al. (2010) Chromatin-remodeling components of the BAF complex facilitate reprogramming. Cell 141, 943-955

94 Peterson, C.L., Dingwall, A. and Scott, M.P. (1994) Five SWI/SNF gene products are components of a large multisubunit complex required for transcriptional enhancement. Proceedings of the National Academy of Sciences of the United States of America 91, 2905-2908

95 Shen, W. et al. (2007) Solution structure of human Brg1 bromodomain and its specific binding to acetylated histone tails. Biochemistry 46, 2100-2110

96 Link, K.A. et al. (2005) BAF57 governs androgen receptor action and androgen-dependent proliferation through SWI/SNF. Molecular and Cellular Biology 25, 2200-2215

97 Aoyagi, S., Trotter, K.W. and Archer, T.K. (2005) ATP-dependent chromatin remodeling complexes and their role in nuclear receptor-dependent transcription in vivo. Vitamins and Hormones 70, 281-307

98 Debril, M.B. et al. (2004) Transcription factors and nuclear receptors interact with the SWI/SNF 
complex through the BAF60c subunit. Journal of Biological Chemistry 279, 16677-16686

99 Trotter, K.W. and Archer, T.K. (2007) Nuclear receptors and chromatin remodeling machinery. Molecular and Cellular Endocrinology 162-167, 265-266

100 Pal, S. et al. (2003) mSin3A/histone deacetylase 2and PRMT5-containing Brg1 complex is involved in transcriptional repression of the Myc target gene cad. Molecular and Cellular Biology 23, 7475-7487

101 Zhang, H.S. et al. (2000) Exit from G1 and S phase of the cell cycle is regulated by repressor complexes containing HDAC-Rb-hSWI/SNF and Rb-hSWI/ SNF. Cell 101, 79-89

102 Subtil-Rodriguez, A. and Reyes, J.C. (2010) BRG1 helps RNA polymerase II to overcome a nucleosomal barrier during elongation, in vivo. EMBO Reports 11, 751-757

103 Lemon, B. et al. (2001) Selectivity of chromatinremodelling cofactors for ligand-activated transcription. Nature 414, 924-928

104 Ryme, J. et al. (2009) Variations in the composition of mammalian SWI/SNF chromatin remodelling complexes. Journal of Cellular Biochemistry 108, 565-576

105 Wang, Z. et al. (2004) Polybromo protein BAF180 functions in mammalian cardiac chamber maturation. Genes and Development 18, 3106-3116

106 Huang, X. et al. (2008) Coronary development is regulated by ATP-dependent SWI/SNF chromatin remodeling component BAF180. Developmental Biology 319, 258-266

107 Burrows, A.E., Smogorzewska, A. and Elledge, S.J. (2010) Polybromo-associated BRG1-associated factor components BRD7 and BAF180 are critical regulators of $\mathrm{p} 53$ required for induction of replicative senescence. Proceedings of the National Academy of Sciences of the United States of America 107, 14280-14285

108 Bowser, R., Giambrone, A. and Davies, P. (1995) FAC1, a novel gene identified with the monoclonal antibody Alz50, is developmentally regulated in human brain. Developmental Neuroscience 17, 20-37

109 Jones, M.H., Hamana, N. and Shimane, M. (2000) Identification and characterization of BPTF, a novel bromodomain transcription factor. Genomics 63, 35-39

110 Wysocka, J. et al. (2006) A PHD finger of NURF couples histone $\mathrm{H} 3$ lysine 4 trimethylation with chromatin remodelling. Nature 442, 86-90

111 Bochar, D.A. et al. (2000) A family of chromatin remodeling factors related to Williams syndrome transcription factor. Proceedings of the National Academy of Sciences of the United States of America 97, 1038-1043

112 Collins, N. et al. (2002) An ACF1-ISWI chromatinremodeling complex is required for DNA replication through heterochromatin. Nature Genetics 32, 627-632

113 Poot, R.A. et al. (2000) HuCHRAC, a human ISWI chromatin remodelling complex contains hACF1 and two novel histone-fold proteins. EMBO Journal 19, 3377-3387

114 Strohner, R. et al. (2001) NoRC-a novel member of mammalian ISWI-containing chromatin remodeling machines. EMBO Journal 20, 4892-4900

115 Ladurner, A.G. et al. (2003) Bromodomains mediate an acetyl-histone encoded antisilencing function at heterochromatin boundaries. Molecular Cell 11, 365-376

116 Zhou, Y. and Grummt, I. (2005) The PHD finger/ bromodomain of NoRC interacts with acetylated histone H4K16 and is sufficient for rDNA silencing. Current Biology 15, 1434-1438

117 Vollmuth, F., Blankenfeldt, W. and Geyer, M. (2009) Structures of the dual bromodomains of the P$\mathrm{TEFb}$-activating protein Brd4 at atomic resolution. Journal of Biological Chemistry 284, 36547-36556

118 Moriniere, J. et al. (2009) Cooperative binding of two acetylation marks on a histone tail by a single bromodomain. Nature 461, 664-668

119 Huang, H.D. et al. (2007) Solution structure of the second bromodomain of Brd2 and its specific interaction with acetylated histone tails. BMC Structural Biology 7, 57

120 Umehara, T. et al. (2010) Structural implications for K5/K12-di-acetylated histone H4 recognition by the second bromodomain of BRD2. FEBS Letters $584,3901-3908$

121 Liu, Y. et al. (2008) Structural basis and binding properties of the second bromodomain of Brd4 with acetylated histone tails. Biochemistry 47, 6403-6417

122 Sun, H. et al. (2007) Solution structure of BRD7 bromodomain and its interaction with acetylated peptides from histone $\mathrm{H} 3$ and $\mathrm{H} 4$. Biochemical and Biophysical Research Communications 358, 435-441

123 Zeng, L. et al. (2008) Structural basis of site-specific histone recognition by the bromodomains of human coactivators PCAF and CBP/p300.

Structure 16, 643-652

124 Hudson, B.P. et al. (2000) Solution structure and acetyl-lysine binding activity of the GCN5 bromodomain. Journal of Molecular Biology 304, 355-370 
125 Kupitz, C., Chandrasekaran, R. and Thompson, M. (2008) Kinetic analysis of acetylation-dependent $\mathrm{Pb} 1$ bromodomain-histone interactions. Biophysical Chemistry 136, 7-12

126 Chandrasekaran, R. and Thompson, M. (2007) Polybromo-1-bromodomains bind histone $\mathrm{H} 3$ at specific acetyl-lysine positions. Biochemical and Biophysical Research Communications 355, 661-666

127 Dhalluin, C. et al. (1999) Structure and ligand of a histone acetyltransferase bromodomain. Nature 399, 491-496

128 Singh, M. et al. (2007) Structural ramification for acetyl-lysine recognition by the bromodomain of human BRG1 protein, a central ATPase of the SWI/ SNF remodeling complex. Chembiochem 8, 1308-1316

129 Tsai, W.W. et al. (2010) TRIM24 links a noncanonical histone signature to breast cancer. Nature 468, 927-932

$130 \mathrm{Wu}$, J.I., Lessard, J. and Crabtree, G.R. (2009) Understanding the words of chromatin regulation. Cell 136, 200-206

131 Gamsjaeger, R. et al. (2011) Structural basis and specificity of acetylated transcription factor GATA1 recognition by BET family bromodomain protein Brd3. Molecular and Cellular Biology 31, 2632-2640

132 French, C.A. et al. (2001) BRD4 bromodomain gene rearrangement in aggressive carcinoma with translocation $t(15 ; 19)$. American Journal of Pathology 159, 1987-1992

133 French, C.A. et al. (2008) BRD-NUT oncoproteins: a family of closely related nuclear proteins that block epithelial differentiation and maintain the growth of carcinoma cells. Oncogene 27, 2237-2242

134 French, C.A. et al. (2003) BRD4-NUT fusion oncogene: a novel mechanism in aggressive carcinoma. Cancer Research 63, 304-307

135 Reynoird, N. et al. (2010) Oncogenesis by sequestration of $\mathrm{CBP} / \mathrm{p} 300$ in transcriptionally inactive hyperacetylated chromatin domains. EMBO Journal 29, 2943-2952

136 Filippakopoulos, P. et al. (2010) Selective inhibition of BET bromodomains. Nature 468, 1067-1073

137 Sobulo, O.M. et al. (1997) MLL is fused to CBP, a histone acetyltransferase, in therapy-related acute myeloid leukemia with a $t(11 ; 16)(q 23 ; p 13.3)$. Proceedings of the National Academy of Sciences of the United States of America 94, 8732-8737

138 Panagopoulos, I. et al. (2001) Fusion of the MORF and CBP genes in acute myeloid leukemia with the $\mathrm{t}(10 ; 16)(\mathrm{q} 22 ; \mathrm{p} 13)$. Human Molecular Genetics 10, 395-404
139 Kasper, L.H. et al. (1999) CREB binding protein interacts with nucleoporin-specific FG repeats that activate transcription and mediate NUP98-HOXA9 oncogenicity. Molecular and Cellular Biology 19, 764-776

140 Deguchi, K. et al. (2003) MOZ-TIF2-induced acute myeloid leukemia requires the MOZ nucleosome binding motif and TIF2-mediated recruitment of CBP. Cancer Cell 3, 259-271

141 Pasqualucci, L. et al. (2011) Inactivating mutations of acetyltransferase genes in B-cell lymphoma. Nature 471, 189-195

142 Bouchal, J. et al. (2011) Transcriptional coactivators p300 and CBP stimulate estrogen receptor-beta signaling and regulate cellular events in prostate cancer. Prostate 71, 431-437

143 Leachman, N.T. et al. (2010) ATAD2B is a phylogenetically conserved nuclear protein expressed during neuronal differentiation and tumorigenesis. Development, Growth and Differentiation 52, 747-755

144 Khetchoumian, K. et al. (2007) Loss of Trim24 (Tif1alpha) gene function confers oncogenic activity to retinoic acid receptor alpha. Nature Genetics 39, 1500-1506

145 Kikuchi, M. et al. (2009) TRIM24 mediates liganddependent activation of androgen receptor and is repressed by a bromodomain-containing protein, BRD7, in prostate cancer cells. Biochimica Biophysica et Acta 1793, 1828-1836

146 Grunwald, C. et al. (2006) Expression of multiple epigenetically regulated cancer/germline genes in nonsmall cell lung cancer. International Journal of Cancer 118, 2522-2528

147 Scanlan, M.J. et al. (2000) Expression of cancer-testis antigens in lung cancer: definition of bromodomain testis-specific gene (BRDT) as a new CT gene, CT9. Cancer Letters 150, 155-164

148 Tong, W.G. et al. (2010) Phase I and pharmacologic study of SNS-032, a potent and selective Cdk2, 7, and 9 inhibitor, in patients with advanced chronic lymphocytic leukemia and multiple myeloma. Journal of Clinical Oncology 28, 3015-3022

149 Crawford, N.P.S. et al. (2008) Bromodomain 4 activation predicts breast cancer survival. Proceedings of the National Academy of Sciences of the United States of America 105, 6380-6385

150 You, J. et al. (2006) Kaposi's sarcoma-associated herpesvirus latency-associated nuclear antigen interacts with bromodomain protein Brd4 on host mitotic chromosomes. Journal of Virology 80, 8909-8919 
151 Weidner-Glunde, M., Ottinger, M. and Schulz, T.F. (2010) WHAT do viruses BET on? Frontiers in Bioscience 15, 537-549

152 Lin, A. et al. (2008) The EBNA1 protein of EpsteinBarr virus functionally interacts with Brd4. Journal in Virology 82, 12009-12019

153 Nicodeme, E. et al. (2010) Suppression of inflammation by a synthetic histone mimic. Nature 468, 1119-1123

154 Mahdi, H. et al. (2009) Specific interaction between genotype, smoking and autoimmunity to citrullinated alpha-enolase in the etiology of rheumatoid arthritis. Nature Genetics 41, 1319-1324

155 Rajendrasozhan, S., Yao, H. and Rahman, I. (2009) Current perspectives on role of chromatin modifications and deacetylases in lung inflammation in COPD. COPD 6, 291-297

156 Choi, K.C. et al. (2009) Gallic acid suppresses lipopolysaccharide-induced nuclear factor-kappaB signaling by preventing RelA acetylation in A549 lung cancer cells. Molecular Cancer Research 7, 2011-2021

157 Jung, H.J. et al. (2010) Anti-inflammatory activity of n-propyl gallate through Down-regulation of NFkappaB and JNK pathways. Inflammation. DOI: 10.1007/s10753-010-9241-0

158 Deng, W.G., Zhu, Y. and Wu, K.K. (2004) Role of p300 and PCAF in regulating cyclooxygenase-2 promoter activation by inflammatory mediators. Blood 103, 2135-2142

159 Cullen, S.J., Ponnappan, S. and Ponnappan, U. (2009) Catalytic activity of the proteasome finetunes Brg1-mediated chromatin remodeling to regulate the expression of inflammatory genes. Molecular Immunology 47, 600-605

160 Alter, M.D. and Hen, R. (2008) Putting a KAP on transcription and stress. Neuron 60, 733-735

161 Jakobsson, J. et al. (2008) KAP1-mediated epigenetic repression in the forebrain modulates behavioral vulnerability to stress. Neuron 60, 818-831

162 Bjarkam, C.R. et al. (2009) Further immunohistochemical characterization of BRD1 a new susceptibility gene for schizophrenia and bipolar affective disorder. Brain and Structure Function 214, 37-47

163 Nyegaard, M. et al. (2010) Support of association between BRD1 and both schizophrenia and bipolar affective disorder. American Journal of Medical Genetics. Part B, Neuropsychiatric Genetics 153B, 582-591

164 Loe-Mie, Y. et al. (2010) SMARCA2 and other genome-wide supported schizophrenia-associated genes: regulation by REST/NRSF, network organization and primate-specific evolution. Human Molecular Genetics 19, 2841-2857

165 Koga, M. et al. (2009) Involvement of SMARCA2/ BRM in the SWI/SNF chromatin-remodeling complex in schizophrenia. Human Molecular Genetics 18, 2483-2494

166 Rouaux, C., Loeffler, J.P. and Boutillier, A.L. (2004) Targeting CREB-binding protein (CBP) loss of function as a therapeutic strategy in neurological disorders. Biochemical Pharmacology 68, 1157-1164

167 Zimmermann, N. et al. (2007) Confirmation of EP300 gene mutations as a rare cause of Rubinstein-Taybi syndrome. European Journal of Human Genetics 15, 837-842

168 Viosca, J. et al. (2010) Syndromic features and mild cognitive impairment in mice with genetic reduction on p300 activity: differential contribution of p300 and CBP to Rubinstein-Taybi syndrome etiology. Neurobiology of Disease 37, 186-194

169 Valor, L.M. et al. (2011) Ablation of CBP in forebrain principal neurons causes modest memory and transcriptional defects and a dramatic reduction of histone acetylation but does not affect cell viability. Journal of Neuroscience 31, 1652-1663

170 Oike, Y. et al. (1999) Truncated CBP protein leads to classical Rubinstein-Taybi syndrome phenotypes in mice: implications for a dominant-negative mechanism. Human Molecular Genetics 8, 387-396

171 Tanaka, Y. et al. (1997) Abnormal skeletal patterning in embryos lacking a single Cbp allele: a partial similarity with Rubinstein-Taybi syndrome. Proceedings of the National Academy of Sciences of the United States of America 94, 10215-10220

172 Saura, C.A. and Valero, J. (2011) The role of CREB signaling in Alzheimer's disease and other cognitive disorders. Reviews in Neurosciences 22, 153-169

173 Bartsch, O. et al. (2002) Molecular studies in 10 cases of Rubinstein-Taybi syndrome, including a mild variant showing a missense mutation in codon 1175 of CREBBP. Journal of Medical Genetics 39, 496-501

174 Petrij, F. et al. (1995) Rubinstein-Taybi syndrome caused by mutations in the transcriptional coactivator CBP. Nature 376, 348-351

175 Narayan, P. and Dragunow, M. (2010) Pharmacology of epigenetics in brain disorders. British Journal of Pharmacology 159, 285-303

176 Sachchidanand et al. (2006) Target structure-based discovery of small molecules that block human p53 and CREB binding protein association. Chemistry and Biology 13, 81-90 
177 Owen, D.J. et al. (2000) The structural basis for the recognition of acetylated histone $\mathrm{H} 4$ by the bromodomain of histone acetyltransferase gcn5p. EMBO Journal 19, 6141-6149

178 Chung, C.W. et al. (2011) Discovery and characterization of small molecule inhibitors of the BET family bromodomains. Journal of Medicinal Chemistry 54, 3827-3838
179 Borah, J.C. et al. (2011) A small molecule binding to the coactivator CREB-binding protein blocks apoptosis in cardiomyocytes. Chemistry and Biology 18, 531-541

180 Zeng, L. et al. (2005) Selective small molecules blocking HIV-1 Tat and coactivator PCAF association. Journal of the American Chemical Society $127,2376-2377$

\section{Further reading, resources and contacts}

\section{Websites}

Bromodomain structures solved by the Structural Genomics Consortium: http:/ / www.sgc.ox.ac.uk/structures/BRO.html

Chemical probe resource for epigenetic targets:

http:/ / www.thesgc.org/chemical_probes/epigenetics/

Disease-annotated chromatin epigenetic resource:

http:/ / wodaklab.org/dancer/

The chromatin database:

http:/ / www.chromdb.org/

Human Histone Modification Database (HHMD):

http:/ / bioinfo.hrbmu.edu.cn/hhmd/

\section{Features associated with this article}

\section{Figures}

Figure 1. Phylogenetic tree of the human bromodomain family and substrate recognition of bromodomains.

Figure 2. Domain organisation of bromodomain proteins and translocations in cancer.

Figure 3. Structural overview of a bromodomain and binding mode of bromodomain inhibitors.

Figure 4. Chemical structures of bromodomain inhibitors.

\section{Tables}

Table 1. Bromodomain-containing proteins and their functions.

Table 2. Bromodomain substrates with known affinity.

\section{Citation details for this article}

Susanne Muller, Panagis Filippakopoulos and Stefan Knapp (2011) Bromodomains as therapeutic targets. Expert Rev. Mol. Med. Vol. 13, e29, September 2011, doi:10.1017/S1462399411001992 